Research Article

\title{
A Birandom Job Search Problem with Risk Tolerance
}

\author{
Guoli Wang, Wansheng Tang, and Ruiqing Zhao \\ Institute of Systems Engineering, Tianjin University, Tianjin 300072, China \\ Correspondence should be addressed to Wansheng Tang,wstang@eyou.com
}

Received 24 April 2012; Accepted 4 October 2012

Academic Editor: Ricardo Perera

Copyright (C) 2012 Guoli Wang et al. This is an open access article distributed under the Creative Commons Attribution License, which permits unrestricted use, distribution, and reproduction in any medium, provided the original work is properly cited.

This paper considers a novel class of birandom job search problem, in which the job offers are sampled by the job searcher from a finite job set with equivalent probability and their wages are characterized as independent but maybe not identically nonnegative random variables. The job searcher knows the job offer's wage distribution when he samples the job offer. Since the offered wage is a random variable and the reservation wage is a deterministic number, it is meaningless to make comparison directly. In order to rank the random wage and the reservation wage and provide decision support, a risk tolerance criterion is designed, and the job searcher then accepts or rejects the sampled job offer depending on whether the risk tolerance criterion is met or not. Since the offered wages are random variables and the search process is random, it's impossible to obtain the job searcher's real return; in this case, its expected value can be calculated via birandom theory. Simultaneously, some propositions on the expected return as well as the average search times are also studied which may provide some valuable suggestions to the job searcher. Numerical examples are given to illustrate the decision process of the risk tolerance-based birandom job search problem.

\section{Introduction}

Search is one of the most important approaches that is devoted to link information aggregation with labor markets. Since Stigler's pioneering papers on search problem [1, 2], many researchers have done tremendously significant works in this field. McCall [3] developed a class of job search model named as sequential search model with a reservation wage. Jovanovic [4] presented a long-run equilibrium theory of turnover to explain the regularities observed by empirical investigators. Shimer [5] investigated a wage bargaining problem in which on-the-job search was permitted. Hagedorn et al. [6] combined principalagent theory with job search theory and adopted a repeated moral hazard framework with unobserved heterogeneity about agents' job opportunities. For more information, readers may refer to [7-11]. 
It is well known that most of the existing papers mainly focus on the job search problem in two cases. One is that the offered wages are assumed to be a series of iid random variables. In fact, the assumption of independence of the offered wages is rational, but assuming they are mutually identical is too strict. For instance, different employers give different wages, generally, the wages often are composed of basic pays and performance bonus, in which the performance bonus varies with different positions; even the basic payments are equivalent. For example, performance bonuses may be influenced by that the seasonal or cyclical factors resulting in the performance bonuses are random variables so do the totally wage offers. Thus, generally, the offered wages are not mutually identical random variables. The other is that the previous works mainly focus on those kinds of job search problems in which the job searcher can get the deterministic wage level when he accepts the job or rejects it. In most cases, the job searcher cannot acquire such kind of exact information on the wage since the wages such as the performance bonuses are usually uncertain. Encouraged by these motivations, we consider a birandom job search problem in which the offered jobs are sampled from a finite job set with equivalent probability and the offered wages given by the potential employers are independent but not necessarily identically distributed random variables. Furthermore, the distribution of the offered wage can be known by the job searcher after the sample. By virtue of the twofold randomness, the problem considered is a novel problem. In order to provide a criterion for the job searcher to accept or reject the sampled job, a risk tolerance criterion is designed, and it can be interpreted as a probability that the offered wage is not less than the reservation wage exceeds a confidence level given in advance. Thus, the risk tolerance criterion may ignore some differences among offered wages since different supported random variables may be all acceptable offered wages under the risk tolerance criterion. Generally, the risk tolerance level is dependent on the job searcher's risk aversion degree, that is, different people may have different risk tolerance levels. The job searcher only accepts the offer whose offered wage meets the risk tolerance criterion. Meanwhile, due to the search return with twofold uncertainty, it is impossible to obtain the job searcher's real revenue before searching. Therefore, we consider the expected return instead. In order to compute the expected return, this paper also discusses the average search times' computing method and propositions on the expected return as well as the average search times. A series of interesting results are obtained in the discussion process which may provide some valuable suggestions to the job searcher.

The rest of the paper is organized as follows. In Section 2, some basic concepts are recalled such as birandom variable and expected value operator of birandom variable. Section 3 presents a novel class of job search problem in which the offered wages may be independent but not identically distributed random variables and a risk tolerance criterion is introduced. Simultaneously, the average search times and the expected return of the birandom job search problem are discussed and several interesting properties are obtained. Section 4 makes a comparison between this paper and McCall's work from several aspects. Section 5 presents several numerical examples to demonstrate the search process of the designed model. Finally, Section 6 gives the conclusions and further scopes.

\section{Basic Concepts}

Several useful definitions such as birandom variable and expected value of birandom variable are recalled. 
Definition 2.1 (see [12]). A birandom variable $X$ is a mapping from a probability space $(\Omega, A, \operatorname{Pr})$ to a collection of random variables, such that for any Borel subset $B$ of the real number set $\mathfrak{R}$, the induced function $\operatorname{Pr}\{X(\omega) \in B\}$ is a measurable function with respect to $\omega \in \Omega$.

Example 2.2. Let $\Omega=\left\{\omega_{1}, \omega_{2}, \ldots, \omega_{N}\right\}$, and $\operatorname{Pr}\left\{\omega_{i}\right\}=p_{i}, i=1,2, \ldots, N$. Assume that $X$ is a function defined on $(\Omega, \mathcal{A}, \operatorname{Pr})$ as follows:

$$
X(\omega)=\left\{\begin{array}{lc}
X_{1}, & \text { if } \omega=\omega_{1} \\
X_{2}, & \text { if } \omega=\omega_{2} \\
\vdots & \vdots \\
X_{N}, & \text { if } \omega=\omega_{N}
\end{array}\right.
$$

where $X_{i}$ is a random variable, $i=1,2, \ldots, N$. Then $X$ is a birandom variable.

Definition 2.3 (see [12]). Let $X$ be a birandom variable defined on the probability space $(\Omega, \mathcal{A}, \operatorname{Pr})$. Then the expected value of birandom variable $X$ is defined as

$$
\mathrm{E}[\mathrm{X}]=\int_{0}^{+\infty} \operatorname{Pr}\{\omega \in \Omega \mid \mathrm{E}[X(\omega)] \geq t\} \mathrm{d} t-\int_{-\infty}^{0} \operatorname{Pr}\{\omega \in \Omega \mid \mathrm{E}[X(\omega)] \leq t\} \mathrm{d} t
$$

provided that at least one of the above two integrals is finite.

Remark 2.4. In Definition 2.3, the first "E" represents the expected value operator with respect to the birandom variable, while the second " $E$ " is the expected value operator in a manner of ordinary random variable. The two are identical when the birandom variable degenerates to an ordinary random variable.

Example 2.5. Let $X$ be the birandom variable given in Example 2.2, the expected value of $X$ can be calculated as [12]

$$
\mathrm{E}[\mathrm{X}]=\sum_{i=1}^{N} p_{i} \mathrm{E}\left[\mathrm{X}_{i}\right]
$$

\section{Search Problem with Uncertainty Wage}

Consider a job search problem with $N$ job offers in the labor market. The wages of the $N$ job offers, denoted as $X_{1}, X_{2}, \ldots, X_{N}$ are assumed to be independent but maybe not identically nonnegative random variables.

The search process can be demonstrated as follows: first the job searcher samples one job from the job set with equivalent probability. If the job searcher is satisfied with the sampled job's wage level, then he will stop searching and accept the job; otherwise, the job searcher gives up the sampled job and continues to sample one from the remaining jobs with equivalent probability and then repeats the judgment. Repeat this process until an appropriate job offer is accepted. 


\subsection{Risk Tolerance Criterion}

Due to the uncertainty of the offered wage, therefore, it is meaningless to compare a random variable with a deterministic reservation wage directly. In order to rank a random wage and a reservation wage, a risk tolerance criterion is designed. Risk tolerance criterion requires that the probability that the offered wage is not less than the reservation wage exceeds a confidence level given in advance by the job searcher. That is,

$$
\begin{aligned}
& \text { accept offered wage } X \text { if } \operatorname{Pr}\{X \geq r\} \geq \alpha, \\
& \text { continue to search if } \operatorname{Pr}\{X \geq r\}<\alpha,
\end{aligned}
$$

where $r$ denotes the reservation wage and $\alpha$ denotes the risk tolerance.

Criterion (3.1) indicates that the job searcher bears a risk of $1-\alpha$ that the realized wage may be less than the reservation wage. This is the reason of naming it as risk tolerance.

Remark 3.1. In McCall's model [3], the criterion for the job searcher is to reject those offers that the realizations of their wages are below the reservation wage and to accept any offer that the realization of its wage is above the reservation wage. Intuitively, for any realization $x$, the criterion has the form

accept the offered wage $x$ if $x \geq r$,

continue to search if $x<r$,

where $x$ is a realization of the wage.

Different from McCall's idea, in this paper, the wages of the job offers that the job searcher samples from the job set are assumed to be random variables, what he can observe is only their probability distributions, not the realizations of the wages. The job searcher therefore cannot make a comparison directly between the wages and the reservation wage. Additionally, the job searcher using reservation wage criterion will always find a job since he/she has known the wage distribution before search, while under risk tolerance criterion the job searcher may not. These indicate that there exist significant differences between these two criterions.

Two main commons can be strengthened between the risk tolerance criterion and the reservation wage. One is that both criterions are called for decision making, although reservation wage criterion needs the realization of wage offer while the risk tolerance not. The other is that the two criterions are all devised before the searching process, such as the determination of reservation wage according to wage distribution in reservation wage criterion and the risk tolerance level and reservation wage in risk tolerance criterion. 


\subsection{Average Search Times}

Let $K$ denote the occurred times of the event " $\operatorname{Pr}\{X \geq r\} \geq \alpha$ first happened so far". It is obvious that $K$ is a random variable with the probability mass function

$$
\begin{gathered}
\operatorname{Pr}\{K=1\}=\frac{M}{N}, \\
\operatorname{Pr}\{K=k\}=\left(1-\frac{M}{N}\right)\left(1-\frac{M}{N-1}\right) \cdots\left(1-\frac{M}{N-(k-2)}\right) \frac{M}{N-(k-1)}, \quad 2 \leq k \leq N-M+1, \\
\operatorname{Pr}\{K=\infty\}=1-\sum_{k=1}^{N} \operatorname{Pr}\{K=k\},
\end{gathered}
$$

where $M$ is the number of the offered wages $X_{i}$ which meet the risk tolerance criterion, $\operatorname{Pr}\left\{X_{i} \geq r\right\} \geq \alpha, i=1,2, \ldots, N$, and $\infty$ is the theoretical search times when $M=0$.

Remark 3.2. If $X_{1}, X_{2}, \ldots, X_{N}$ are independent and identically distributed random variables, then

$$
\operatorname{Pr}\{K=1\}= \begin{cases}1, & \text { if } \exists X_{i}, \text { such that } \operatorname{Pr}\left\{X_{i} \geq r\right\} \geq \alpha, \\ 0, & \text { otherwise. }\end{cases}
$$

This means that the job searcher either searches only one time and accepts an offer or never can find an appropriate offer.

Furthermore, the average search times

$$
\begin{aligned}
\mathrm{E}[K] & =\sum_{k=1}^{N} k \cdot \operatorname{Pr}\{K=k\}+\infty \cdot \operatorname{Pr}\{K=\infty\} \\
& = \begin{cases}\sum_{k=1}^{N} k \cdot \operatorname{Pr}\{K=k\}, & \text { if } \exists X_{i}, \text { such that } \operatorname{Pr}\left\{X_{i} \geq r\right\} \geq \alpha, \\
\infty, & \text { otherwise. }\end{cases}
\end{aligned}
$$

Moreover, let

$$
Q= \begin{cases}N-M+1, & \text { if } M>0 \\ \infty, & \text { if } M=0\end{cases}
$$

$Q$ is called the maximum search times.

Theorem 3.3. Let $X_{1}, X_{2}, \ldots, X_{N}$ be $N$ offered wages, $K$ the search times, and $r$ the reservation wage. Then the maximum search times $Q$ is a nondecreasing function with respect to $r$. 
Proof. For any real numbers $r_{1}, r_{2} \in \mathfrak{R}^{+}, r_{1}<r_{2}$. Let $M_{1}$ and $M_{2}$ be the numbers of the offered wages meeting the following risk tolerance conditions:

$$
\begin{aligned}
& \operatorname{Pr}\left\{X_{i} \geq r_{1}\right\} \geq \alpha, \\
& \operatorname{Pr}\left\{X_{i} \geq r_{2}\right\} \geq \alpha,
\end{aligned}
$$

with $i=1,2, \ldots, N$, respectively.

Then

$$
\begin{aligned}
& Q_{1}= \begin{cases}N-M_{1}+1, & \text { if } M_{1}>0, \\
\infty, & \text { if } M_{1}=0,\end{cases} \\
& Q_{2}= \begin{cases}N-M_{2}+1, & \text { if } M_{2}>0, \\
\infty, & \text { if } M_{2}=0 .\end{cases}
\end{aligned}
$$

since

$$
\operatorname{Pr}\left\{X_{i} \geq r_{1}\right\} \geq \operatorname{Pr}\left\{X_{i} \geq r_{2}\right\}
$$

hence, $M_{1} \geq M_{2} \geq 0$. By (3.8), $Q_{2} \geq Q_{1}$. The proof is complete.

Theorem 3.4. The maximum search times are a nondecreasing function with respect to the risk tolerance $\alpha$.

Proof. It follows from the monotonicity of

$$
\operatorname{Pr}\left\{X_{i} \geq r\right\} \geq \alpha,
$$

with respect to $\alpha$ and the definition

$$
Q= \begin{cases}N-M+1, & \text { if } M>0, \\ \infty, & \text { if } M=0\end{cases}
$$

immediately.

\subsection{Expected Return}

Let $X_{i_{n}}$ be the $n$th sample result, $i_{n} \in\{1,2, \ldots, N\}$ and $c$ the search cost which incurs each time a job offer is sampled. The job searcher is assumed to attain an acceptable offer so that the return from stopping after the $n$th search is given by

$$
Y_{n}=\text { sample }\left\{X_{i_{1}}, X_{i_{2}}, \ldots, X_{i_{n}}\right\}-n c,
$$


where sample $\left\{X_{i_{1}}, X_{i_{2}}, \ldots, X_{i_{n}}\right\}=X_{i_{n}}$, which implies that the previous $n-1$ sampled job offers' wages do not meet the risk tolerance, namely,

$$
\operatorname{Pr}\left\{X_{i_{j}} \geq r\right\}<\alpha, \quad j=1,2, \ldots, n-1,
$$

but, $\operatorname{Pr}\left\{X_{i_{n}} \geq r\right\} \geq \alpha$ holds truly.

Let $Z_{K}$ denote the job searcher's return. If $M \neq 0$, then

$$
Z_{K}(\omega)= \begin{cases}Y_{1}, & \text { if } K\left(\omega_{1}\right)=1 \\ Y_{2}, & \text { if } K\left(\omega_{2}\right)=2 \\ \vdots & \vdots \\ Y_{N-M+1}, & \text { if } K\left(\omega_{N-M+1}\right)=N-M+1\end{cases}
$$

If $M=0$, then $Z_{K}(\omega)=-\infty \cdot c=-\infty$. The job searcher's expected return can be calculated as

$$
\mathrm{E}\left[Z_{K}\right]=\sum_{k=1}^{N-M+1} \operatorname{Pr}\{K=k\} \mathrm{E}\left[Y_{k}\right]
$$

where

$$
\begin{gathered}
\mathrm{E}\left[Y_{1}\right]=\frac{1}{M} \mathrm{E}\left[X^{1}+X^{2}+\cdots+X^{M}\right]-c, \\
\mathrm{E}\left[Y_{k}\right]=\frac{1}{M} \mathrm{E}\left[X^{1}+X^{2}+\cdots+X^{M}\right]-k c, \quad 2 \leq k \leq N-M+1,
\end{gathered}
$$

and $X^{1}, X^{2}, \ldots, X^{M}$ are the $M$ risk tolerance met offered wages.

Remark 3.5. If $X_{1}, X_{2}, \ldots, X_{N}$ are independent and identically distributed offered wages, then

$$
\mathrm{E}\left[Z_{K}\right]= \begin{cases}\mathrm{E}\left[X_{1}\right]-c, & \text { if } M=N, \\ -\infty, & \text { if } M=0 .\end{cases}
$$

The job searcher's expected return is not necessarily increasing with respect to the reservation wage $r$, that is, the job searcher cannot improve his expected return through raising his reservation wage. Similarly, the job searcher lowering the reservation wage will not necessarily decrease his expected return.

The job searcher's expected return is not necessarily increasing with respect to the risk tolerance $\alpha$, that is, the job searcher cannot improve his expected return through raising his risk tolerance. Similarly, the job searcher lowering the risk tolerance will not necessarily decrease his expected return.

Theorem 3.6. The expected return $\mathrm{E}\left[Z_{K}\right]$ is a decreasing function of search cost $c$.

Proof. It follows from (3.15) immediately. 
Remark 3.7. Theorem 3.6 illustrates that an increase of the search cost will definitely decrease the job searcher's expected return, but it will not affect the first search times' success rate $\operatorname{Pr}\{K=1\}$.

\section{Comparison with McCall's Work}

Towards a better understanding of the problem considered here, we make a comparison with the most relevant work of McCall [3] as follows.

The distributions of the offered wages are assumed to be independent but not necessarily identically distributed in this paper while they are assumed to be independent and identical in McCall's work. An offered wage the job searcher gets every time after the search is a random variable in this paper while in McCall's work it is a realization which can be observed by the job searcher. The number of the job offers is finite in this paper while it is infinite in McCall's work.

The risk tolerance criterion devised in this paper requires that the probability that the offered wage is not less than the reservation wage exceeds a confidence level given in advance by the job searcher; it is obvious that the job searcher bears a risk of $1-\alpha$ that his real wage may be less than the reservation wage given $\alpha$ the risk tolerance level. Different from the risk tolerance criterion, the reservation wage criterion designed in [3] requires that the realized wage is not less than the reservation wage. Thus, it is apparent that the reservation wage criterion depends on the realization of the job offer and under this condition the job searcher bears no risk that the realized wage may be less than the reservation wage. Objectively speaking, the risk tolerance criterion represents a novel class of stopping criterion, and to some extent it ignores the difference of the uncertain wages.

\section{Numerical Examples}

Example 5.1. Suppose that $X_{1}, X_{2}$, and $X_{3}$ are three offered wages with probability density functions

$$
\begin{aligned}
& f_{1}(x)= \begin{cases}\frac{x}{25}-\frac{35}{25}, & \text { if } 35 \leq x<40, \\
\frac{-x}{25}+\frac{45}{25}, & \text { if } 40 \leq x \leq 45, \\
0, & \text { otherwise. }\end{cases} \\
& f_{2}(x)= \begin{cases}\frac{x}{25}-\frac{40}{25}, & \text { if } 40 \leq x<45, \\
\frac{-x}{25}+\frac{50}{25}, & \text { if } 45 \leq x \leq 50, \\
0, & \text { otherwise, }\end{cases}
\end{aligned}
$$




$$
f_{3}(x)= \begin{cases}\frac{x}{25}-\frac{145}{25}, & \text { if } 145 \leq x<150 \\ \frac{-x}{25}+\frac{155}{25}, & \text { if } 150 \leq x \leq 155 \\ 0, & \text { otherwise }\end{cases}
$$

Moreover, the reservation wage $r=44$, the search cost $c=0.5$, and the risk tolerance $\alpha=0.5$. Thus, the acceptable offered wages are $X_{2}$ and $X_{3}$. The job searcher stops searching after the first and the second search times; by (3.16) his expected value will be

$$
\begin{gathered}
\mathrm{E}\left[\text { sample }\left\{X_{i_{1}}\right\}-c\right]=\frac{1}{2}\left(\mathrm{E}\left[X_{2}+X_{3}\right]\right)-0.5=97.0, \\
\mathrm{E}\left[\text { sample }\left\{X_{i_{1}}, X_{i_{2}}\right\}-2 c\right]=\frac{1}{2}\left(\mathrm{E}\left[X_{2}+X_{3}\right]\right)-1=96.5,
\end{gathered}
$$

respectively. Thus, by (3.15) the expected return under random search times is

$$
\mathrm{E}\left[\text { sample }\left\{X_{i_{1}}, X_{i_{2}}, \ldots, X_{i_{n}}\right\}-n c\right]=\frac{2}{3} \times 97.0+\frac{1}{3} \times 96.5=96.83
$$

If the job searcher increases the reservation wage to $r=50$, then the acceptable offered wage is only $X_{3}$ and he may stop searching after the first, the second, and the third search times; by (3.16) his expected value will be 149.5, 149.0, and 148.5, respectively. Thus, by (3.15) the expected return under a random search times is

$$
\mathrm{E}\left[\text { sample }\left\{X_{i_{1}}, X_{i_{2}}, \ldots, X_{i_{n}}\right\}-n c\right]=\frac{1}{3} \times 149.5+\frac{1}{3} \times 149.0+\frac{1}{3} \times 148.5=149.0 .
$$

Remark 5.2. The offered wages $X_{2}$ and $X_{3}$ are acceptable when the reservation wage $r=44$, the search cost $c=0.5$, and the risk tolerance $\alpha=0.5$; but obviously, their supports are very different; thus, to some extent, the stopping criterion ignores the difference between the uncertain wages.

Next, the following example shows that an increase of $r$ may also decrease the expected return.

Example 5.3. Suppose that $X_{1}, X_{2}$, and $X_{3}$ are three offered wages with probability density functions $f_{1}(x), f_{2}(x)$, and $f_{3}(x)$, respectively, where $f_{1}(x), f_{2}(x)$ remain the same as in Example 5.1, and

$$
f_{3}(x)= \begin{cases}\frac{x}{25}-\frac{45}{25}, & \text { if } 45 \leq x<50 \\ \frac{-x}{25}+\frac{55}{25}, & \text { if } 50 \leq x \leq 55 \\ 0, & \text { otherwise. }\end{cases}
$$


Moreover, the reservation wage $r=44$, the search cost $c=0.5$, and the risk tolerance $\alpha=$ 0.5 . Thus, the acceptable offered wages are $X_{2}$ and $X_{3}$. The job searcher may stop searching after the first and the second search times; by (3.16) his expected value will be 47.0 and 46.5 , respectively. Thus, by (3.15) the expected return under a random search times is

$$
\mathrm{E}\left[\text { sample }\left\{X_{i_{1}}, X_{i_{2}}, \ldots, X_{i_{n}}\right\}-n c\right]=\frac{2}{3} \times 47.0+\frac{1}{3} \times 46.5=46.83
$$

If the job searcher increases the reservation wage to $r=51$, then he may just stop searching after the third search times since there is no wage offer that can meet the risk tolerance criterion; by (3.16) his expected value will be $-\infty$.

Examples 5.1 and 5.3 provide a general result about the relationship between the reservation wage $r$ and the expected return. From the discussion, we know that a change of $r$ will affect the expected return but increase or decrease is uncertain.

Example 5.4. Suppose that $X_{1}, X_{2}$, and $X_{3}$ are three offered wages which remain the same as in Example 5.1, respectively. Moreover, the reservation wage $r=45$, the search cost $c=0.5$, and the risk tolerance $\alpha=0.5$. Thus, the acceptable offered wages are $X_{2}$ and $X_{3}$. The job searcher may stop searching after the first and the second search times; by (3.16) his expected value will be 97.0 and 96.5 , respectively. Thus, by (3.15) the expected return under a random search times is

$$
\mathrm{E}\left[\text { sample }\left\{X_{i_{1}}, X_{i_{2}}, \ldots, X_{i_{n}}\right\}-n c\right]=\frac{2}{3} \times 97.0+\frac{1}{3} \times 96.5=96.83
$$

If the job searcher increases the risk tolerance to $\alpha=0.8$, then he may stop searching after the first, the second, and the third search times; by (3.16) his expected value will be 149.5, 149.0, and 148.5, respectively. Thus, by (3.15) the expected return under a random search times is

$$
\mathrm{E}\left[\text { sample }\left\{X_{i_{1}}, X_{i_{2}}, \ldots, X_{i_{n}}\right\}-n c\right]=\frac{1}{3} \times 149.5+\frac{1}{3} \times 149.0+\frac{1}{3} \times 148.5=149.0 .
$$

Example 5.5. Suppose that $X_{1}, X_{2}$, and $X_{3}$ are three offered wages which remain the same as in Example 5.3, respectively. Moreover, the reservation wage $r=50$, the search $\operatorname{cost} c=0.5$, and the risk tolerance $\alpha=0.5$. Thus, the acceptable offered wage is $X_{3}$. The job searcher may stop searching after the first, the second, and the third search times, by (3.16) his expected value will be $49.5,49.0$, and 48.5 , respectively. Thus, by (3.15) the expected return under a random search times is

$$
\mathrm{E}\left[\text { sample }\left\{X_{i_{1}}, X_{i_{2}}, \ldots, X_{i_{n}}\right\}-n c\right]=\frac{1}{3} \times 49.5+\frac{1}{3} \times 49.0+\frac{1}{3} \times 48.5=49.0 .
$$

If the job searcher increases the risk tolerance to $\alpha=0.8$, then he may just stop searching after the third search times; by (3.16) his expected value will be $-\infty$.

Examples 5.4 and 5.5 show that an increase of the risk tolerance may increase or decrease the job searcher's expected search return when keeps other conditions unchanged. 
For the same reason, a risk tolerance' rise can avoid the influence of some lower wages to end the search process. But, no matter how reservation wage or risk tolerance varies the job searcher cannot always expect a more expected return. The uncertainty explains the job searcher's dilemma: to seek a higher wage by raising the reservation wage or risk tolerance and the unexpected result of reducing his expected return.

\section{Conclusions}

This paper investigated a new class of job search problem in which the offered wages were assumed to be independent but not identically distributed random variables and sampled with equivalent probability; thus, the search return of the job searcher was a birandom variable. For making decision, a risk tolerance criterion was designed which only depending on a judgment the probability that the offered wage is not less than the reservation wage exceeds a predetermined confidence level. Simultaneously, the influence of the variation of the parameters such as reservation wage, risk tolerance, and search cost was discussed, and some interesting results were obtained. Moreover, the further research may include studying the case that the reservation wage changes over search process and setting it as random variable in a manner of dynamic programming, considering search problem in fuzzy environment in which offered wages are considered as subjective assessments, analyzing hidden information of both job searcher and potential employer, via principal-agent theory designing optimal contract, associating with behavioral economics and econometrics presenting some empirical analysis.

\section{Acknowledgments}

This work is supported by the National Natural Science Foundation of China (No. 71071106) and supported partially by the Program for Changjiang Scholars and Innovative Research Team in University (No. IRT 1028), and the Program for New Century Excellent Talents in the Universities of China.

\section{References}

[1] G. Stigler, “The economics of information," Journal of Political Economy, vol. 69, no. 3, pp. 213-225, 1961.

[2] G. Stigler, "Information in the labor market," Journal of Political Economy, vol. 70, no. 5, pp. 94-104, 1962.

[3] J.J. McCall, "Economics of information and job search," Quarterly Journal of Economics, vol. 84, no. 1, pp. 113-128, 1970.

[4] B. Jovanovic, "Job-matching and the theory of turnover," Journal of Political Economy, vol. 87, no. 5, pp. 972-990, 1979.

[5] R. Shimer, “On-the-job search and strategic bargaining," European Economic Review, vol. 50, no. 4, pp. 811-830, 2006.

[6] M. Hagedorn, A. Kaul, and T. Mennel, "An adverse selection model of optimal unemployment insurance," Journal of Economic Dynamics and Control, vol. 34, no. 3, pp. 490-502, 2010.

[7] C. A. Pissarides, "Equilibrium in the labor market with search frictions," American Economic Review, vol. 101, no. 4, pp. 1092-1105, 2011.

[8] D. M. Ramsey, "A large population job search game with discrete time," European Journal of Operational Research, vol. 188, no. 2, pp. 586-602, 2008. 
[9] S. Brown, J. Roberts, and K. Taylor, "Reservation wages, labour market participation and health," Journal of the Royal Statistical Society Series A, vol. 173, no. 3, pp. 501-529, 2010.

[10] G. Menzio and S. Shi, "Efficient search on the job and the business cycle," Journal of Political Economy, vol. 119, no. 3, pp. 468-510, 2011.

[11] D. T. Mortensen and R. Wright, "Competitive pricing and efficiency in search equilibrium," International Economic Review, vol. 43, no. 1, pp. 1-20, 2002.

[12] J. Peng and B. Liu, "Birandom variables and birandom programming," Computers and Industrial Engineering, vol. 53, no. 3, pp. 433-453, 2007. 


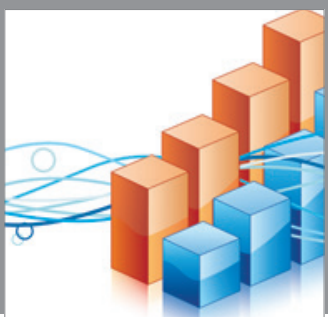

Advances in

Operations Research

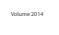

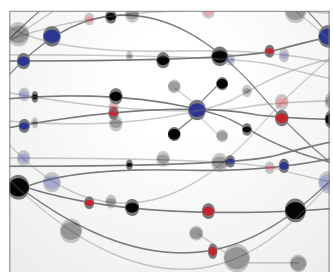

\section{The Scientific} World Journal
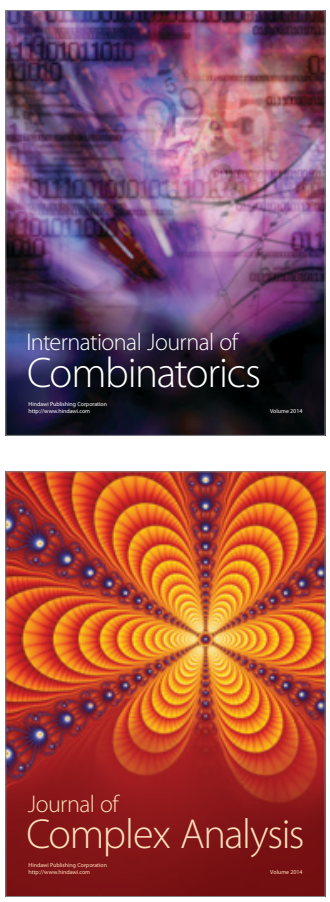

International Journal of

Mathematics and

Mathematical

Sciences
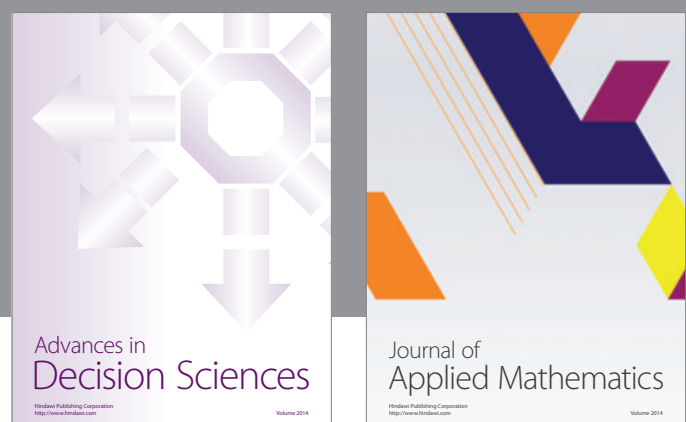

Journal of

Applied Mathematics
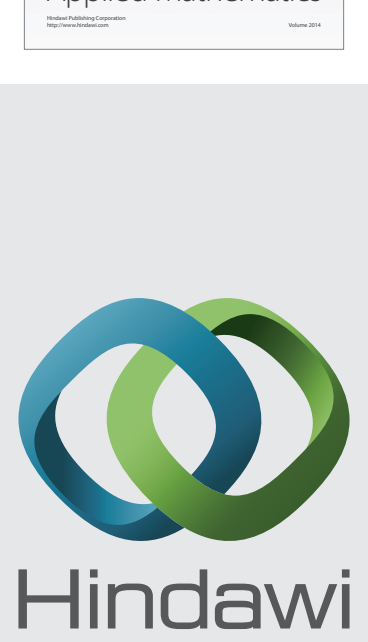

Submit your manuscripts at http://www.hindawi.com
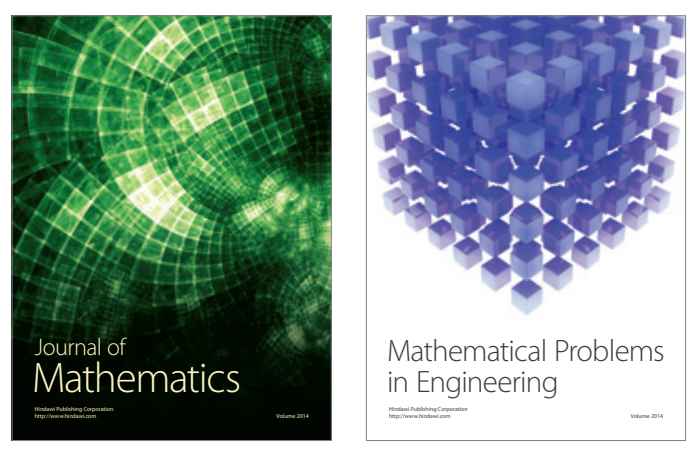

Mathematical Problems in Engineering
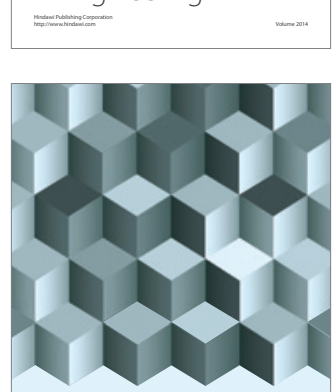

Journal of

Function Spaces
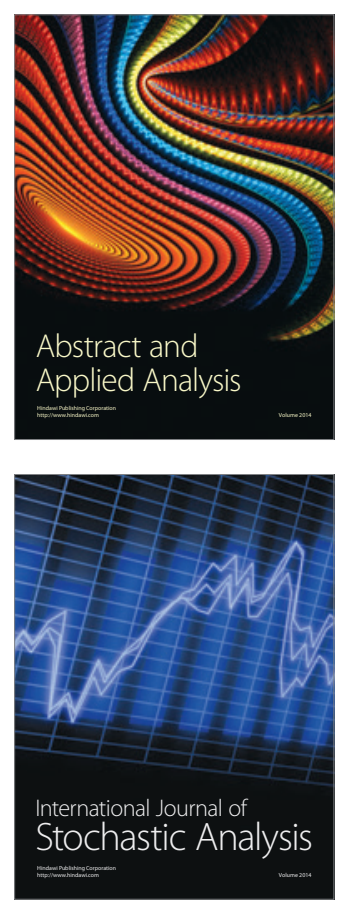

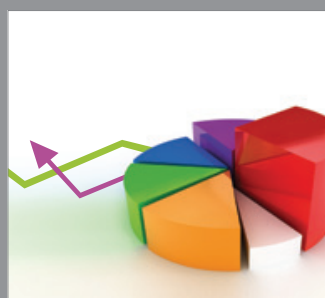

ournal of

Probability and Statistics

Promensencen
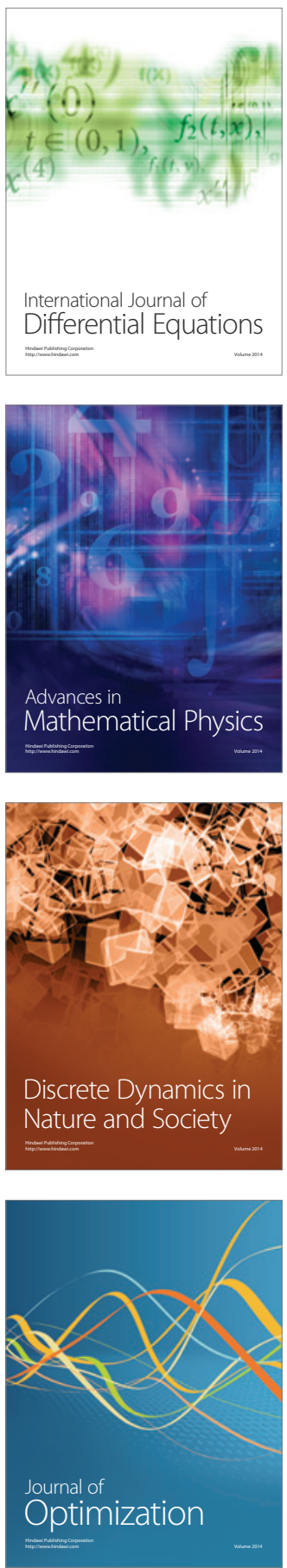